\title{
VAMOS AO BAILE: GINGAS DA COMUNICAÇÃO E DA PARTICIPAÇÃO NO ZAPATISMO*
}

Guilherme Gitahy de Figueiredo

"Bailan en el aire piensamientos belicosos. Todas las palabras son fuertes [...]"

TÁssio Franchi

Nas celebrações zapatistas sempre acontece um baile (Rovira, 1997). Este artigo aborda o baile que constitui as novas maneiras de se fazer política do zapatismo. Parte-se dos resultados da dissertação de 2003, publicada no livro A guerra é o espetáculo: origens e transformações da estratégia do Exército Zapatista de Libertação Nacional (EZLN) (Figueiredo, 2006). Nele, tomou-se a "estratégia" como padrões das práticas, dos discursos e das formas de organização ligados aos objetivos e à sobrevivência de um movimento, desenvolvendo-se a idéia de que houve uma lenta mas radical mudança na estratégia zapatista, que deixou o modelo clássico de guerrilha para consolidar-se, em 1996, como construção de "um mundo onde caibam muitos mundos" através do processo de criação de "mecanismos de participação e comunicação". Agora, ousa-se adensar a análise dos desdobramentos

\footnotetext{
* Este artigo contou com as contribuições do coletivo "Pensamento Radical", especialmente Leo Vinicius Liberatto, Pablo Ortellado e Marco Fernandes. Devo ainda às críticas preciosas de Nashieli Rangel, Leda Gitahy, Tássio Franchi e, sobretudo, Adrián Gurza Lavalle, bem como à inspiração do grupo de dança contemporânea Micrantos.
} 
desses "mecanismos" a partir de $1994^{1}$, antes mesmo de sua consolidação. O processo político instaurado por eles não é do tipo em que um sujeito planeja, executa e tem um resultado previsível, como na "fabricação" de Arendt (2002): relação entre "sujeito" e "objeto". A nova estratégia zapatista desenvolve-se na confluência de inúmeros performers, cuja interação gera e é gerada por aqueles mecanismos de participação e comunicação. Isto remete ao conceito de "ação", que Arendt contrapõe a "fabricação": a "ação" desperta inúmeras reações de outros sujeitos, de maneira que seus resultados não são previsíveis e perdem-se de vista nas teias inefáveis das relações sociais - é relação entre "sujeito" e "sujeito".

Â luz de Geertz (1989), considera-se que para todas as práticas a sociedade atribui significados, de maneira que elas são "discurso social", encerrando sempre uma dimensão comunicativa. No caso da "participação", mas não somente, os zapatistas concordariam com isso: costumam referir-se a ela como "trazer sua palavra". Mas se para Geertz os significados pertencem a uma "concepção" que é "pública", comum aos membros de uma "cultura", para este trabalho é mais adequada a abordagem individualista de Certeau (1994): as práticas são sempre "artes de fazer", nas quais cada sujeito inventa, a partir de seu repertório de práticas e significados, um discurso social que não é mera reprodução de uma cultura, mas que também opera desvios, produz a nova cultura através de colagens ${ }^{2}$. Ora, se as práticas do povo são sempre "artes de fazer", podemos ousar o estudo delas como se faz na teoria literária ou na história da arte: a partir de suas tópicas.

\footnotetext{
${ }^{1}$ Sobre o período anterior, o autor não dispõe de dados suficientes para ir além das reflexões do livro.

${ }^{2}$ Certeau (1994) usa o termo bricolage, inspirando-se na imagem dos pequenos trabalhos manuais domésticos em que as pessoas transformam os produtos e sucatas da sociedade urbano-industrial, dando-lhes novos usos e significados.
} 
Para fazer referência às práticas desviantes do zapatismo, que ressignificam a política, tentar-se-á construir um novo conceito de "performance". Ao invés do estabelecimento de uma definição prévia, esta construção será feita ao longo do texto, mediante os usos deste termo e dos contextos de sua aplicação. A escolha do termo inspira-se na experiência do autor deste artigo com rádio arte, rádio livre e filmagens de dança contemporânea, bem como no livro de Cohen (2004). Este afirma que a performance tem como características a redução das fronteiras entre os gêneros artísticos e entre a arte e a vida, a ênfase no ato de criação desenvolvido ao vivo nos espetáculos (improvisação ou criação mais lenta e elaborada, em contraposição à mera execução, reprodução de um script pronto por um ou mais atores) e a quebra das convenções artísticas e sociais, entre elas as que se referem aos padrões de espaço e tempo da produção artística. É, ideologicamente, uma "reversão da mídia": diante de um sistema social que atinge e escraviza os artistas em suas malhas multimídia, a performance é um discurso radical que, através de colagens ${ }^{3}$, recusa o mundo dado e abre caminhos de linguagem para os desejos de mundos distintos do hegemônico. No prefácio escrito em 2002 à segunda edição de seu livro, Cohen menciona o "zapatismo" e "rádios livres" como formas contemporâneas da arte performática que ele estudou nos anos 1980. Porém, ele não explicita a maneira pela qual seu conceito se ampliou da arte para a comunicação e a política.

Este termo serve também para escapar parcialmente às ambigüidades do conceito de "espetáculo", que terá aqui apenas o sentido de ação ou discurso social com grande visibilidade $^{4}$. O espetáculo, freqüentemente, é mediado

\footnotetext{
${ }^{3}$ Cohen (2004) usa o termo collage, numa referência à técnica artística "inventada" por Max Ernst e inspirada no papier collés.

4 No livro A guerra é o espetáculo, "espetáculo" possui sentido amplo, que inclui desde a comunicação mediada pela indústria cultural até ações com pouca visibilidade e a noção de performance.
} 
pela mídia corporativa, o que costuma implicar a relação unilateral em que poucos exercem grande controle sobre a produção de significado das práticas sociais. Porém, podemos considerar ao menos duas situações em que o espetáculo acontece escapando ao controle desta mídia: aquela que resulta da somatória de inúmeras pequenas ações comunicativas (por exemplo os e-mails com comunicados do EZLN, reproduzidos por milhares de pessoas ao redor do mundo) e a situação em que se produz uma performance que a grande mídia não pode ignorar e cujo significado ela não consegue controlar; exemplo disso foi o sangrento levante zapatista de 1994, em que o EZLN ocupou sete centros urbanos de Chiapas e teve como primeira resposta o enfrentamento militar por parte do Exército Mexicano. Não era possível, até por razões de $\operatorname{mercado}^{5}$, a grande mídia não noticiar esse evento e, por maior que fosse a manipulação informativa, os aspectos mais importantes 50 deste discurso social escaparam ao seu controle ${ }^{6}$. Os tradicionais conquistados ocuparam os centros urbanos, símbolos do poder do colonizador, nós da comunicação política, econômica e simbólica, e fizeram ecoar a partir deles o seu grito de "ya basta!". O grito foi banhado a sangue, mas ao mesmo tempo foi entrando uma nova performer na cena: a chamada "sociedade civil" mexicana, que começou a se

\footnotetext{
${ }^{5}$ A violência, junto com o erotismo, é a mercadoria que mais rende na indústria cultural moderna. Segundo Trejo (1994), nunca um assunto teve tanto destaque em tão pouco tempo nos meios mexicanos, o que ele atribui à "espetacularidade" e à rapidez dos acontecimentos. Sobretudo as empresas que transformaram o tema em causa própria, editorial, tiveram grandes aumentos de venda. Foi o caso do La Jornada que, em 13 de janeiro, após a mobilização maciça da véspera, anunciou uma tiragem de 164 mil exemplares, três vezes maior do que a sua média diária. Gordillo y Ortiz (1994) descreve uma influência semelhante do zapatismo no mercado de livros, embora não especule sobre as suas causas.

${ }^{6}$ Além da dificuldade da mídia corporativa em controlar o significado de suas notícias, é preciso mencionar que não havia as condições para uma censura governamental: a repressão mexicana vinha tendo a peculiaridade de se exercer menos pela censura do que através da cooptação de oposicionistas e da prisão e assassinato de quem persistisse no questionamento político.
} 
mobilizar aos milhares, chegando a algo entre 50 e 100 mil no protesto do centro da cidade do México do dia 12 de janeiro. Os civis pediram "alto a la masacre" e "justicia y paz", apoiando as demandas da guerrilha e questionando os meios violentos. Era a maior mobilização civil desde os comícios pós-eleitorais de protesto contra a fraude eleitoral de 1988 e contou com a presença do ex-candidato a presidente pelo PRD, derrotado pela fraude Cualtemoc Cárdenas. No mesmo dia, o Governo, que tinha diante de si uma propaganda internacional em pedaços e uma nova eleição presidencial a ser realizada ainda naquele ano, anunciou o cessar fogo unilateral. Entre 19 de fevereiro e 3 de março de 1994 ocorreu a primeira rodada de "diálogos 7" entre o Governo e a guerrilha, que, diante da possibilidade de aliança com uma sociedade civil pacifista, nunca mais esquentou o cano de suas armas. Porém, nem toda performance é espetacular e, freqüentemente, ela desdenha o espetáculo. Milhares de grupos e indivíduos pelo mundo começaram a ressignificar localmente as notícias e relatos do levante e a inventar híbridos do zapatismo com suas próprias tradições. Ao mesmo tempo, a inspiração zapatista serviu para o surgimento de novas teias e redes entre esses grupos, e deles com o EZLN, feitas de conexões com pouca visibilidade justamente porque criativas, e tão numerosas quanto imprevisíveis. Contribuíram para esta comunicação rizomática o barateamento e a popularização de aparelhos eletrônicos "domésticos", como gravadores, câmeras fotográficas e filmadoras, e a rápida ampliação do uso aberto da internet, que, segundo Briggs e Burke (2004), passou de rede dedicada à pesquisa acadêmica a "rede das redes", aberta a todos entre setembro de 1993 e

\footnotetext{
7 O EZLN frisou que se tratava de "diálogos" e não "negociação", pois os representantes da guerrilha não tinham autorização para concluir um acordo e tinham que levar às comunidades as propostas de acordo elaboradas com o Governo para serem submetidas à sua aprovação ou rejeição.
} 
março de $1994^{8}$. A versão política do uso aberto e horizontal da internet foi fortemente estimulada pelo zapatismo.

Ao iniciar o "diálogo" com o Governo a guerrilha elevou a sociedade civil, e não o Estado, à sua principal interlocutora. Respondeu publicamente a inúmeras cartas enviadas por performers os mais diversos, como outros movimentos indígenas, partidos políticos, ONGs, o movimento estudantil da Unam ou crianças de uma escola, e elaborou mensagens destinadas ao "povo mexicano", aos "povos e governos do mundo" e, particularmente, a alguns órgãos da imprensa considerados potenciais aliados senão da guerrilha, ao menos da democracia e da "paz com justiça e dignidade". Começou durante a guerra e ganhou intensidade a partir de meados de janeiro o esforço do EZLN para superar as dificuldades geográficas e militares para receber e enviar uma quantidade incrível de textos. Nos primeiros sete meses, a guerrilha produziu 107 comunicados $^{9}$, o que 52 equivale a um texto a cada dois dias. Em apenas um mês foram 37 textos, entre meados de janeiro e o começo do diálogo com o Governo na Catedral de San Cristóbal de Las Casas (EZLN, 1994), o que mostra um grande esforço inicial com a finalidade de justificar a ação armada e propor um sentido comum, tópicas e papéis para a ação política nacional na luta contra o regime e pela paz e a democracia. Somente com ela se poderiam alcançar outros objetivos econômicos e sociais. Como afirma Certeau (1994, p. 211), "há relatos que marcham na frente para fundar um cam-

\footnotetext{
${ }^{8}$ A primeira rede (Arpanet) foi instalada nos EUA em 1968/1969, para conectar algumas universidades e centros de pesquisa, financiada pelo Governo através da Administração dos Projetos de Pesquisa Avançada do Departamento de Defesa dos EUA (Arpa). Para o Pentágono, o essencial era que esta rede seria capaz de sobreviver à retirada ou destruição de qualquer computador ligado a ela e mesmo à destruição nuclear de toda infra-estrutura de comunicações. A visão das universidades era que a rede daria "acesso livre" aos professores e pesquisadores e que eles eram comunicadores (Briggs e Burke, 2004).

${ }^{9}$ Contando-se apenas aqueles que foram tornados públicos e publicados nas compilações da editora ERA.
} 
po". Para o EZLN, o diálogo interno e com a sociedade civil é que fundava o campo - os comunicados respondiam às iniciativas democráticas e às cartas dos grupos da sociedade civil e eram, eles mesmos, construídos como pontes entre diversas etnias. Os textos assinados pelo Comitê Clandestino Revolucionário Indígena - Comando Geral (CCRI-CG) do EZLN tinham que ser discutidos e aprovados pelo Comitê, composto por representantes das comunidades indígenas, o que exigia um trabalho de tradução entre as várias línguas e visões de mundo internas: "quatro grupos de comitês clandestinos, controlados por quatro etnias principalmente" (EZLN, 1994, p. 169). O subcomandante Marcos, líder militar e sobretudo importante porta-voz do EZLN, referiase a esta comunicação dialógica, através da qual se construía um campo democrático, ao iniciar a tópica da "palavra": em 28 de maio de 1994 falou de todas "as minorias na hora de falar, e maiorias na hora de calar e agüentar. Todos os intolerados procurando uma palavra, sua palavra, o que devolva a maioria aos eternos fragmentados, nós" (EZLN, 1994, p. 243). A união se daria através da "palavra", sendo esta a interlocução, "sistema de enlaces" $" \mathrm{e}$ traduções entre as diversas minorias. A "palavra" era também muitas vezes contraposta à "violência" nos comunicados, embora, até o começo de 1995, o EZLN tenha mantido a ameaça de retorno à luta armada para forçar a criação e aceitação dos espaços de "diálogo" com o Governo, da "palavra" entre as minorias, exigir a democratização do Estado e o reconhecimento da autonomia local e regional, servindo ainda como apelo à disposição de dar a vida, um sacrifício que renovou a radicalidade e as emoções ligadas a esses valores e causas. "Nossas vidas valem um mundo melhor"11.

\footnotetext{
${ }^{10}$ Tradução: sistema de conexões.

${ }^{11}$ Não há uma oposição necessária entre a violência e processos democráticos. É verdade que, freqüentemente, a violência é empregada contra a democracia e, em Chiapas, a repressão colocou obstáculos sérios para a realização, por exemplo,
} 
Os textos do EZLN e de Marcos rompiam com a tradição pretensamente racional e científica dos escritos políticos modernos e se tornaram célebres pelo senso de humor, uma ideologia inovadora que rompia com o jargão banalizado do marxismo, o sincretismo entre o mundo maia e o ocidental, o uso de recursos estilísticos tomados da literatura ocidental, da tradição oral maia, das cartas comuns e, entre outros aspectos, se apropriava da simbologia da Revolução Mexicana que havia dominado o discurso estatal até começar a ser abandonada com o começo do neoliberalismo em 1982. As versões mais livres e irreverentes dos comunicados - por exemplo, as declarações políticas através da poesia - começaram a ser escritas por Marcos em textos que carregavam a sua assinatura e que originalmente serviam para apresentar os comunicados do CCRI-CG do EZLN e personalizar a comunicação com os diversos destinatários, o que contribuía para evitar o tom impessoal e criar um 54 sentido de valorização da diversidade e de diálogo entre os diferentes. O êxito dessa liberdade estilística evidenciou-se no seu avanço sobre os textos mais importantes do EZLN: suas formas mais heterodoxas começaram nas cartas assinadas por Marcos, especialmente nos post scripts de suas cartas, e foram ganhando mais e mais destaque até que na Quarta Declaração da Selva Lacandona, de janeiro de 1996, a poesia ganhou pleno direito a dar forma aos posicionamentos políticos mais importantes da guerrilha. Os textos do EZLN e da sociedade civil, além da circulação de pessoas,

\footnotetext{
de assembléias ou para a circulação mais livre e horizontal de informações entre as comunidades indígenas e com pessoas de fora - pelo temor aos "informantes" do governo e à detração do movimento que, facilmente confundível com a crítica, também serve para facilitar a ação repressiva. Por outro lado, Briggs e Burke (2004) mostram como a formação da esfera pública - debates, crítica, opinião pública, participação política, uso da impressão gráfica etc. - no período que antecedeu a "era moderna" esteve intimamente ligada a momentos de conflito social como a Reforma, as guerras religiosas, a guerra civil inglesa, a Revolução Gloriosa e a Revolução Francesa.
} 
imagens, áudios e vídeos, contribuíram para que as ações, figurinos, como o pasamontañas, as armas e as roupas tradicionais indígenas, e cenários, como a selva e as montanhas, começassem a compor repertórios de tópicas praticadas e comentadas que, além de atraentes para públicos e produtores de mídias monopólicas e participativas, intensificaram o caráter performático da disputa política. Vale lembrar que a literatura e outras artes se distinguem das ciências e das engenharias por se permitirem a utilização de linguagens verbais, plásticas e sonoras "coloquiais", e por isso não dependem de um saber monopolizado por especialistas. Contrapunha-se ao Estado autoritário, tecnocrático e científico aquilo que tradicionalmente foi classificado de "irracionalidade" e que no zapatismo aparece como uma outra forma de razão: a "palavra", a comunicação horizontal, esteticamente enraizada nas tradições locais, livre em suas traduções e invenções, feita da interlocução entre a "razão que brota do coração" de cada uma das minorias, entre as diversas identidades, constituindo o espaço democrático. Para tanto, era preciso lançar mão da criatividade, tecedora de pontes entre os diferentes. Das palavras do EZLN e de Marcos depreende-se a visão de que ser livre é lutar, lutar é inventar, movimento que se anima a partir da dor e através da dignidade herdada dos antepassados. É por este caminho que os mortos renascem da morte, que é o esquecimento, e os vivos revivem da morte em vida da longa noite da dominação. Juntam-se, assim, num mesmo movimento de emancipação, as noções de tradição, invenção, memória, ruptura e luta. Diferentemente da liberdade iluminista que é ruptura em um tempo linear, a zapatista sincretiza a linearidade ocidental com o tempo maia, em que as épocas são como diferentes camadas do presente. A liberdade zapatista é um movimento de conexões, traduções e ressignificações, a partir de repertórios tradicionais e, na comunicação horizontal com o "outro", a "palavra". 
O trato com a grande imprensa mereceu táticas inovadoras: ao invés de tratá-la publicamente como se fosse homogênea e vendida, ou então imparcial, espelho e não sujeito ativo na sociedade, elegeu em seu seio três órgãos de imprensa para lhes conferir acesso privilegiado a informações, elogios públicos e um tratamento personalizado através de cartas que, embora fossem públicas, lhes eram diretamente destinadas. Meios considerados hostis, como a Televisa, foram sumariamente proibidos de entrar nas áreas controladas pelo EZLN. Num comunicado de 11 de fevereiro de 1994, assinado por Marcos e destinado ao jornal $E l$ Sur, que tinha protestado contra esse tratamento que privilegiava alguns meios, Marcos declara que eles foram escolhidos por terem políticas editoriais pluralistas, com espaço para várias correntes ideológicas e interpretações da realidade. O La Jornada fora escolhido em particular por causa do grande empenho de seus jornalistas em buscar informações nos locais dos acontecimentos enfrentando "fogo e chumbo"; o El Financiero, graças à profundidade analítica, distante da arrogância intelectual do chamado "jornalismo de elite", e a revista Processo, por sua "objetividade". "Recordem os senhores que nossos companheiros não chegaram à luta armada assim, sem mais nem menos, pelo afã de aventuras. Passaram já por um longo trecho de lutas políticas, legais, pacíficas e econômicas. Também sabem quem os escutou ontem e quem lhes fechou portas e ouvidos" (EZLN, 1994, p. 139). Tratava-se de estabelecer alianças tácitas com parte da imprensa, com base na experiência pregressa dos zapatistas como militantes e catequistas nos movimentos indígenas legais e pacíficos estimulados pela Igreja, a partir dos anos 1960, em Chiapas. Essas empresas passaram a publicar na íntegra os comunicados do EZLN, além de cobrir as suas performances. Um exemplo do êxito da aproximação com alguns dos grandes meios de difusão foi o jornal $L a$ Jornada ter dedicado ao zapatismo o seu Suplemento Espe- 
cial de Aniversário de 20 Anos do jornal, em setembro de 2004, parodiando as comemorações de 20 anos do EZLN e reforçando, assim, uma identidade com a causa zapatista. $\mathrm{Na}$ indústria cultural, vale destacar também a inserção que se deu graças à atração que o zapatismo exerceu sobre atores, poetas e outros artistas famosos, como, por exemplo, as bandas Control Machete, Range Against The Machine, Maná, Paralamas do Sucesso, Chico Science, Nação Zumbi, Mundo Livre S. A., Mano Chau e outras, das quais muitas chegaram a compor e gravar músicas dedicadas ao zapatismo. As performances do EZLN e da sociedade civil ofereciam imagens e sons atraentes para o espetáculo multimídia, e até mesmo a "selva", a "lama" e a "chuva" para um contato mais tátil aos que resolvessem visitar o conflito in loco e realizar atividades de solidariedade. Ações cujo alcance escapa à análise que se pretenda mais "racional" ou "científica", assim como a ambigüidade e a fugacidade das práticas cotidianas de resistência prestam-se pouco à dissertação estática e coerente. Ações mais bem digeridas pelos relatos (Certeau, 1994), saborosas para e-mails, sites, mídias radicais, comunicadores populares e até mesmo jornalistas e periódicos que aderiram à construção dos "diálogos" com o Estado e da "palavra" entre as minorias. É curioso que justamente o La Jornada, grande jornal que mais se aproximou do zapatismo, se destaque por um tipo de texto que se aproxima mais do relato.

Uma tópica constante da cena zapatista, entre tantas outras, é aquela que surgiu na Primeira Declaração da Selva Lacandona e no traçado percorrido pelos levantados de primeiro de janeiro de 1994 como sendo o "avanço libertador até a capital do país". Mas como toda tópica artística, foi ganhando novos significados ao longo dos anos, despistando qualquer intérprete exageradamente literal da expressão, o Governo em particular. A trajetória feita a pé e a fogo nos primeiros dias chegou até San Cristóbal 
de Las Casas. As imagens foram além da capital, deram a volta ao mundo. Os comunicados tinham que ser levados por trilhas, estradas e meios eletrônicos, tardando dias para chegar à imprensa e serem publicados na capital do país. A tópica do "avanço libertador" está ligada a um elemento fundamental da estratégia do EZLN: evitar o isolamento que, segundo Marcos, levara outras revoltas à derrota. Era preciso unificar as forças populares do país, interpretadas por Marcos como sendo "todas as minorias na hora de falar, e maiorias na hora de calar e agüentar" (EZLN, 1994, p. 243). Mas ao invés do EZLN se oferecer como cabeça para este novo corpo (vanguarda) e construir sua identidade (hegemonia), propôs a "palavra" como forma de transformação social, adotando uma postura com maior capacidade de aglutinar os novos movimentos independentes e ONGs que floresciam fragmentariamente, desde meados dos anos 1980, nas margens de um regime corporativo em decomposição, cujas marcas eram a diversidade na composição e a adoção de valores democráticos. Enquanto a estratégia gramsciana envolve a construção de uma cultura democrática (hegemonia) a partir dos repertórios populares, tarefa a ser realizada pelos "intelectuais orgânicos" e pelo "partido", a "palavra" pressupõe a horizontalidade entre os diversos sujeitos da interlocução política, sendo esta forma de comunicação a precursora e o resultado da transformação social democrática. Se na Primeira Declaração o CCRI disse, de maneira mais tradicional, um 'unam-se a nós', num comunicado do dia 20 de janeiro de 1994 os líderes indígenas afirmavam que eram eles que queriam se unir à sociedade civil que havia se mobilizado. Vale dizer que foi o próprio EZLN que relançou a expressão "sociedade civil", sugerindo assim um papel - o de principal sujeito capaz de impedir a guerra e construir a democracia ${ }^{12}$ - que seria apropriado

${ }^{12}$. Na Segunda Declaração da Selva Lacandona, o EZLN define a "sociedade civil" 
e ressignificado pelos novos movimentos independentes. A guerrilha apresentou-se como mais uma força a somar-se na força nacional que animasse o país

"pelo caminho de justiça, democracia e liberdade que nós queremos [...]. Nós pensamos que a mudança revolucionária no México não será produto da ação em um único sentido. Quer dizer, não será, em sentido estrito, uma revolução armada ou uma revolução pacífica. Será, primordialmente, uma revolução que resulte da luta em várias frentes sociais, com muitos métodos, sob diferentes formas sociais, com graus diversos de compromisso e participação. E seu resultado será, não o de um partido, organização ou aliança de organizações triunfante com sua proposta social específica, senão uma sorte de espaço democrático de resolução da confrontação entre diversas propostas políticas" (EZLN, 1994, pp. 95-98).

A tópica do "avanço libertador" iniciou-se com marchas militares. Em 1995, o subcomandante Marcos começou a usar bastante um personagem que tinha criado em 1994 em seus comunicados: Durito, um escaravelho e cavaleiro andante que fuma cachimbo como Marcos, personagem cômico que ele utiliza sobretudo para fazer o escárnio de si mesmo e lançar suas teorias de estilo mais acadêmico e ocidental (muito heterodoxas, como não poderia deixar de

como sendo o "povo", no qual reside a "soberania" e o direito de alterar a forma de governo. Geralmente, faz-se um uso prático dessa expressão para referir-se aos movimentos sociais independentes do tradicional corporativismo estatal - até mesmo o movimento "El Barzón", formado por empresários, camponeses, donas de casa e comerciantes endividados com a crise econômica - e também a segmentos não organizados politicamente, quando se refere mais amplamente às minorias que, juntas, são as maiorias. Trata-se, porém, de uma tópica cujas práticas devem ser entendidas à luz da "palavra", ou seja, a "sociedade civil" como sendo o conjunto de sujeitos que se unem e exercem a democracia, ao mesmo tempo em que a constroem através de formas horizontais de comunicação e solidariedade, procurando forçar o Estado a "mandar obedecendo". 
ser) e que, no começo de 1995, foi o primeiro zapatista a avançar até a cidade do México através dos contos fantásticos de seu autor. Em 1996, durante a realização do I Congresso Nacional Indígena na capital, a despeito da proibição governamental o EZLN enviou a comandante Ramona, uma mulher de carne e osso, indígena, baixinha e portadora de uma doença terminal, para participar do evento sob a proteção da sociedade civil, simbolizando o rompimento físico por parte do EZLN do cerco militar e o seu avanço corporal, pela primeira vez, até o centro do país. Segundo Marcos, ela era a "arma mais beligerante" que possuíam. Em 1997, foi a vez de uma caravana com mil cento e onze zapatistas, representando cada uma das comunidades autônomas, viajar sob a proteção da sociedade civil até a cidade do México para participar da fundação da Frente Zapatista de Libertação Nacional (FZLN). Em 1999, aconteceu uma novidade: durante a terceira grande consulta à sociedade civil com perguntas elaboradas pelo EZLN, cinco mil indígenas zapatistas saíram de Chiapas em direção a todos os cantos do país e até para o exterior, buscando uma comunicação menos voltada ao centro do país. Em 2001, pela primeira vez, a marcha zapatista levou consigo Marcos até a capital, onde ele falou numa rádio livre, e a comandante Esther e outros comandantes discursaram no Congresso da União e em vários espaços, com destaque para a praça central da cidade e instituições universitárias. Cada uma dessas operações envolveu uma preparação de meses e o trabalho organizativo de milhares de pessoas nas comunidades de Chiapas e na sociedade civil, o que mostra a enorme importância atribuída ao espetáculo e à performance, além de serem formas de envolvimento direto da sociedade civil no esforço para combater as fronteiras colocadas pela militarização do país e produzir os espaços de "diálogo" com o Governo e da "palavra" entre as minorias. Ora, avançar corporalmente até a capital do país acabou por desdobrar-se 
em várias metáforas de união, solidariedade e comunicação, entre outros significados ligados à construção da "palavra" no país e, sobretudo a partir de 1996, no mundo. Mas que transformações acompanharam a dança da "palavra"?

No "avanço libertador", o EZLN herdou um aspecto da esquerda tradicional: concebeu a participação política, a democracia, ou seja, a "palavra", como dependente primordialmente de interações com caráter deliberativo e situações de comunicação que Thompson (2001) chama de "face a face". A guerrilha pegou em armas para derrubar o Governo autoritário e implantar, por onde avançasse, a realização de eleições efetivamente democráticas, bem como as instâncias para a autogestão local, municipal e regional. Por outro lado, procurou estabelecer uma comunicação epistolar e inserir-se ativamente na grande mídia. Com a oportunidade de aliança com outros segmentos da sociedade através da renúncia a ações armadas, o EZLN começou a promover espaços alternativos de comunicação e deliberação "face a face", mas que nem por isso deixavam de lembrar, como palcos de bailes performáticos do EZLN com a sociedade civil, os aspectos do realismo fantástico da literatura latinoamericana. O primeiro "diálogo" com o Governo, realizado na Catedral de San Cristóbal de Las Casas em 1994, foi uma oportunidade para o EZLN convocar ativistas de todo o país para participar do "cinturón de paz $z^{13}$ ", garantindo a segurança do evento e uma primeira aproximação ao redor do que começava a ser a expansão da identidade da sociedade civil e suas redes de comunicação e solidariedade. Terminados os primeiros "diálogos" na Catedral, Marcos e os comandantes indígenas levaram a proposta de acordo elaborada com o Governo para ser aprovada em consulta nas comunidades zapatistas. Ao mesmo tempo, a consulta era levada também aos centros urbanos. Era o primeiro exemplo com

${ }^{13}$ Cercos civis para proteger os participantes dos "diálogos". 
grande visibilidade de um dos princípios de raiz indígena que norteiam o zapatismo: o "mandar obedecendo", que vem da noção tradicional de que ser autoridade em uma comunidade é ser servidor e não chefe, algo que no contexto urbano-industrial lembra as utopias originais de participação direta e representação política com controle popular. Marcos estava submetido aos comandantes indígenas do CCRI e estes estavam subordinados às suas comunidades, subordinação efetivada através das situações "face a face" das consultas, reuniões e assembléias que correspondem às instâncias deliberativas das comunidades autônomas e do EZLN. A principal forma zapatista de deliberação, por sua vez, vem da noção comunitária de "consenso", ou seja, é preciso que todos concordem para que seja tomada uma decisão e, do contrário, prolonga-se a discussão. $\mathrm{O}$ "mandar obedecendo" e o "consenso" tiveram ampla influência na sociedade civil nacional e internacional ${ }^{14}$. Outras consultas seriam ainda realizadas, tanto nas comunidades como no país e no mundo. A de 1995 contou com a participação de 1.088.094 pessoas no país, 81 mil no exterior e mobilizou cerca de 80 mil pessoas para a sua organização, seguida, dias depois, pela consulta juvenil que contou com a participação de mais de 200 mil jovens entre 12 e 17 anos. Nela, a sociedade civil legitimou as demandas zapatistas, apoiou a democratização do país e a proposta de participação eqüitativa das mulheres em cargos políticos, e opinou sobre a tática a ser seguida para a organização da luta zapatista civil: se deveria formar uma organização própria e independente ou unir-se a outras forças para formar uma única organização. Venceu a primeira opção, por pequena margem, o que levou à formação da Frente Zapatista de Libertação Nacio-

\footnotetext{
${ }^{14}$ Zibechi (2004) faz um interessante balanço das diferentes influências do zapatismo em movimentos sociais da América Latina dando destaque a formas de organização horizontal, de participação direta, autonomistas, e do questionamento à busca do poder político como forma de transformação social.
} 
nal (FZLN). A consulta de 1999, por sua vez, incluiu a saída de 5.000 zapatistas de Chiapas e a participação de mais de 3 milhões de pessoas que se pronunciaram esmagadoramente favoráveis ao cumprimento do Acordo de San Andrés (se falará disso adiante), selado com o Governo em 1996, e à desmilitarização de Chiapas.

A consulta de 1994 levou meses e deu tempo também para o EZLN repensar sua estratégia que, após o levante, tinha conduzido o "avanço libertador" a possibilidades de significação surpreendentes. Em 12 de junho o CCRI lançou a sua Segunda Declaração da Selva Lacandona, anunciou que as comunidades tinham recusado as ofertas do Governo por elas não tocarem "o ponto essencial do problema: a falta de justiça, de liberdade e democracia" (EZLN, 1994, pp. 269-278), e convocou a Convenção Nacional Democrática (CND), que reuniu de 6 a 10 de agosto de 1994 mais de 6 mil ativistas de todo o país em plena Selva Lacandona, num espaço especialmente construído com algumas técnicas utilizadas pelos antigos maias para construir as pirâmides e chamado "Aguascalientes, Chiapas, um quartel, um bunker, uma fábrica de armas, um centro de treinamento militar, um armazém de explosivos. Aguascalientes, Chiapas, a Arca de Noé, a Torre de Babel, o barco selvático de Fitzcarraldo, o delírio do neozapatismo, o navio pirata" (palavras de abertura de Marcos em: EZLN, 1994, p. 305). O nome do espaço fazia referência ao encontro realizado pelos revolucionários mexicanos de 1914 para dar início à elaboração de um Programa de Reformas ao país recém-"libertado", ainda com a presença dos generais mais radicais Villa e Zapata. A proposta do EZLN era dar tempo e espaço à "palavra" e que a sociedade civil mexicana usasse a CND para elaborar um programa de democratização e reforma constitucional que pudesse ser adotado pelo candidato vencedor das eleições presidenciais, ou que fosse colocado em prática através da "insurgência civil", no caso de prevalecer a fraude e outras 
formas de reprodução do regime de partido único então vigente. Seria também o espaço de produção da nova democracia através da participação direta e de novas formas de representação política, a democracia construindo-se desde as bases da sociedade. Mas a CND, que reuniu ainda 1.500 pessoas em 4 de novembro na capital de Chiapas, Tuxtla, e 4 mil pessoas em fevereiro de 1995 em Querétaro, não teve tanto fôlego. O que se costuma afirmar é que a diversidade de atores e a luta pelo poder acabaram por levar à sua desarticulação. Por outro lado, foi também espaço para o cultivo das "novas maneiras de se fazer política" almejadas pelo EZLN, de formas horizontais de comunicação e solidariedade e de intensificação do estilo performático: a lona que cobria o palanque da $1^{\text {a }}$ CND lhe dava uma forma de barco, em referência ao navio de Fitzcarraldo ${ }^{15}$ (1982), que sonhou em construir uma ópera na Selva Amazônica etc.

A repetição da fraude eleitoral, do uso do poder público e do apoio dos meios de difusão como forma de garantir a continuidade do regime não foi seguida pela "insurgência civil" como havia sido decidido pela CND, a não ser em Chiapas, onde parte dos movimentos indígenas independentes e o PRD local haviam se alinhado momentaneamente com a estratégia zapatista (pois em outros momentos privilegiavam a luta econômica, enquanto o EZLN sempre colocou em primeiro plano a luta política). O clima era de tensão, a guerra podia estalar a qualquer momento. A repressão contra os movimentos independentes aumentou e o EZLN (1995, p. 46) denunciou que os efetivos do Exército Mexicano apertavam o cerco às suas posições e já tinham saltado de 10 mil homens, em janeiro, para 50 mil. Em 8 de outubro anun-

\footnotetext{
${ }^{15}$ Fitzcarraldo (1982), para realizar o sonho de construir uma ópera na Selva, comprou terras com seringueiras cujo acesso seria possível atravessando-se um barco por cima de um morro. Ele tentou usar indígenas para atravessar seu barco, mas foram os indígenas que o usaram para, depois de atravessar o barco, soltá-lo nas corredeiras do rio em oferenda aos deuses.
} 
ciou novamente a ruptura dos "diálogos" com o Governo por causa do crescimento das tensões e das dificuldades de comunicação com os representantes oficiais (EZLN, 1995, pp. 67-100). Em 12 de outubro uma grande passeata indígena comemorou os 502 anos de resistência em San Cristóbal de Las Casas, e a Central Independente de Obreros y Campesinos - Independente (Cioac-Independente, pois a essa altura já havia uma Cioac-Oficial) anunciou a criação de 9 municípios autônomos e pluriétnicos, afirmando que não se tratava de separatismo, mas da construção local, por parte dos indígenas, de seus próprios governos de transição à democracia. Enquanto isso, o EZLN voltou a ameaçar novamente o uso das armas. No dia 8 de dezembro anunciou o fim da trégua, e entre os dias 11 e 19 contornou as posições do Exército Mexicano e apareceu em 38 municípios de Chiapas, rompendo o cerco e declarando a criação de 30 municípios rebeldes que passariam a nomear suas próprias autoridades. Ao mesmo tempo, tentou incitar o líder nacional do PRD, Cárdenas, a se unir na insurgência civil. Lançou, em janeiro, a Terceira Declaração da Selva Lacandona, que retomava em parte o sentido de urgência e ruptura da Primeira Declaração, tentando com isto estimular a mobilização da sociedade civil. E propôs a luta através de "todos os meios, em todos os níveis e em qualquer lugar" por "democracia, liberdade e justiça”, trazendo implícitas aí a participação política de um movimento armado como o EZLN e sua ameaça de voltar a usar a violência, se fosse necessário, explicitando a proposta de unir a CND aos partidos políticos independentes (leia-se: PRD) em um Movimento Pela Libertação Nacional (MLN), sob a liderança de Cárdenas, para derrubar o Executivo, formar um governo de transição e uma nova constituinte. Buscava-se democratizar o país a partir da desobediência civil e da construção da autonomia nas localidades, e garantir este exercício democrático através da "transformação radical" do "pacto nacional". 
Porém, foi apenas com o avanço militar do Exército Mexicano de fevereiro de 1995 que a sociedade civil se mobilizou novamente num espetáculo de massas. $\mathrm{O}$ avanço pôs fim ao controle do EZLN sobre uma parte do território de Chiapas, prendeu vários supostos zapatistas, levou milhares de indígenas a refugiar-se na mata e destruiu o Aguascalientes de Guadalupe Tepeyac. O protesto na cidade do México contra a repressão chegou a mais de 100 mil pessoas sob o lema "todos somos Marcos", e ganhou vulto a presença de protestos internacionais, inclusive de personalidades do mundo artístico e intelectual, mostrando que se tornara custoso ao Governo colocar em prática planos de extermínio. Este teve que restringir sua estratégia de contra-insurgência à que passou a ser classificada "guerra de baixa intensidade", com ações de intimidação, prisões, torturas e assassinatos em pequena escala, difíceis de ganhar destaque na mídia ou nas denúncias dos observadores de direitos humanos, investindo em propaganda e em "políticas públicas" para quem se opusesse à guerrilha, e armando as "guardas brancas", milícias ligadas aos proprietários que passavam, com o novo apoio, a ser chamados de "grupos paramilitares". Em 19 de março a Coordenação de Organismos não-Governamentais pela Paz (Conpaz) e o Centro de Direitos Humanos Frey Bartolomé de Las Casas anunciaram a instalação de nove Acampamentos Civis pela Paz na "zona de conflito", que em 2 anos iriam saltar para 30, criando escudos humanos, postos avançados de observação de direitos humanos e uma infra-estrutura capaz de receber os milhares de visitantes do país e do mundo que começavam a vir a esta nova "Meca" do ativismo internacional irradiar testemunhos sobre Chiapas e as versões da "palavra" que ia sendo formada com a participação deles. Surgiram assim as condições para a retomada dos "diálogos" com o Governo, que iriam ficar conhecidos como Diálogos de San Andrés e que duraram de 19 de abril de 1995 a 2 de setembro de 1996. O EZLN transformou esses "diálo- 
gos" num longo processo que, a cada etapa, exigia a sua volta às comunidades para consultá-las sobre o andamento. Realizou a grande consulta nacional e internacional de 1995 e começou a propor espaços para a participação da sociedade civil tanto nos cinturones de paz como diretamente nos "diálogos", através da nomeação de numerosos assessores entre lideranças e intelectuais, e de fóruns. Além disso, começou a construção de cinco novos Aguascalientes nas regiões Norte, Selva Lacandona e Altos de Chiapas. Depois de fevereiro, o EZLN nunca mais teve em suas performances o tom de ameaça da volta à violência e sua possível força militar estava desacreditada, encontrando-se presa a uma lógica paradoxal: a guerra tornou possível uma aliança com a sociedade civil, e esta aliança só era possível renunciando-se à violência e esta renúncia permitia ao Exército Mexicano estreitar mais e mais o cerco a ponto de tornar inviável um retorno futuro a ações armadas. Em janeiro de 1996 a sociedade civil foi convidada a passar o ano novo nos Aguascalientes, para inaugurar assim suas funções de centros políticos e culturais locais, nacionais e internacionais e para comemorar o aniversário do levante. Os visitantes puderam assistir a vídeos nos quais Marcos declamava a Quarta Declaração da Selva Lacandona: dava ênfase à construção de novos espaços de comunicação "face a face" e ações espetaculares, à linguagem poética, ampliava a dimensão da luta da nação para "um mundo onde caibam muitos mundos" - consolidando uma dimensão internacionalista que passaria a coexistir com o nacionalismo zapatista - e voltava a colocar a "palavra" no centro da proposta política zapatista. Destacava-se a proposta de criação da FZLN a partir dos Comitês Civis de Diálogo que iam se formando localmente para criar uma organização civil, zapatista e independente que, como o EZLN, não ambicionaria a tomada do poder ou a luta pela hegemonia, teria uma direção subordinada às bases e trabalharia para organizar a "sociedade civil", forçando "o que manda a mandar obedecendo". Quando fosse 
possível, o próprio EZLN abandonaria as armas e se uniria à FZLN. Enquanto a tentativa de "diálogo" com o Governo não chegasse a um bom termo, o EZLN permaneceria armado para garantir a autodefesa. A FZLN propôs a ampla participação dos "comitês civis de diálogo" no processo de construção de sua estratégia (formas de organização etc.), e foi adotado o "consenso" das comunidades indígenas como maneira de se tomar decisões.

Por meio da realização de fóruns, a "sociedade civil" elaborou demandas que o EZLN levou às mesas de "diálogo" com o Governo. O primeiro a começar a se reunir foi o Fórum Social Indígena (FSI), que teve iniciados os seus trabalhos em 3 de janeiro de 1996, com a participação de 490 pessoas, 178 organizações indígenas de 32 etnias das 56 existentes no país, que depois iria se transformar no Congresso Nacional Indígena. Seu primeiro encontro foi em 8 de outubro e contou com a participação de 600 delegados, além da comandante Ramona do EZLN, e trouxe o lema "nunca mais um México sem nós". O Governo, que iniciava o ano com índices de recessão e sofria com a falta de boas notícias, acabou fazendo concessões suficientes para que surgisse uma proposta de acordo, que foi aprovada na consulta às comunidades, chegando-se assim, em 16 de fevereiro de 1996, à assinatura dos Acordos de San Andrés. Este versava sobre os Direitos e Cultura Indígenas, tinha por base os debates e deliberações do FSI, e se tivesse sido cumprido resultaria no reconhecimento constitucional da autonomia política, econômica, cultural e jurídica dos municípios e comunidades indígenas. Vale destacar o inciso VII do artigo 4 do Acordo, que garante aos indígenas mexicanos o direito de "adquirir, operar e administrar seus próprios meios de comunicação" ${ }^{16}$.

\footnotetext{
${ }^{16}$ Transcrito da versão do Acordo elaborada pela Comissão de Concórdia e Pacificação (Cocopa) - formada por parlamentares para colaborar com a busca de uma solução negociada com o Governo -, que foi aceita pela Guerrilha, mas recusada pelo Executivo que, por sua, vez elaborou outra versão recusada pelos zapatis- 
Depois deste acordo tiveram início os "diálogos" sobre a segunda mesa temática: "Democracia e Justiça". Para tanto, foi organizado o Fórum para a Reforma do Estado (FRE), que começou em 30 de junho em San Cristóbal de Las Casas e reuniu 1.150 pessoas de 29 estados mexicanos e 130 organizações, inclusive importantes políticos do PRD. Enquanto isso, os primeiros encontros internacionais atraíam milhares de ativistas e organizações de todo o mundo para a Selva. A consolidação de uma estratégia da "palavra" estava aumentando muito a dimensão do zapatismo, e a habilidade inédita do EZLN em colher demandas indígenas nacionais e conseguir transformar grande parte delas em acordo com o Governo começou a aproximar outros atores políticos importantes. Após a assinatura dos Acordos de San Andrés, o EZLN anunciou um acordo com a Coordenadora Intersindical, de um milhão e meio de filiados, para a organização de uma Consulta Nacional sobre Trabalho e Liberdade Sindical. Entre 19 e 21 de julho, o movimento El Barzón, que reunia mais de um milhão de empresários, camponeses, donas de casa e comerciantes endividados com a crise de 1995, realizou um encontro no Aguascalientes de La Realidad. Mas a segunda mesa de diálogo com o Governo não prosperou. Os "diálogos" foram sendo sabotados tanto nos encontros com os comandantes do EZLN quanto através de ações de repressão. Além disso, como o Governo chegou paralelamente a um acordo de reforma eleitoral com os partidos políticos e não estava aceitando a criação de novos mecanismos de participação no Estado, a guerrilha retirou-se do diálogo exigindo condições mínimas para retornar. Ele nunca mais foi retomado. As mesas, que nem chegaram a começar, eram "Bem-Estar e Desenvolvimento" e "Direitos da Mulher em Chiapas".

tas e pela "sociedade civil". Em 2001 foram aprovadas reformas na lei com base nos Acordos, as quais foram, mais uma vez, consideradas insuficientes e que, no que diz respeito aos meios de comunicação, especificavam que a ampliação desses meios entre indígenas deveria submeter-se às leis já existentes sobre a matéria. 
A realização dos fóruns pode ser considerada a última tentativa do EZLN de unificar, em situações de comunicação e deliberação "face a face", as forças nacionais para conseguir diretamente a transformação do Estado. Embora os Acordos de San Andrés nunca tenham sido cumpridos, sua existência lastreou a continuidade do Congresso Nacional Indígena. Acabou por se tornar, também, a principal demanda do EZLN em relação ao Governo, como mostram a Quinta Declaração da Selva Lacandona de julho de 1998 e as perguntas de consulta de 1999. No que diz respeito à maneira tradicional de se fazer uma política democrática, com ênfase em situações de comunicação e deliberação "face a face", o Governo conseguiu isolar o zapatismo, senão em Chiapas, ao menos na temática da autonomia indígena. E a relutância do Governo em criar condições mínimas para a retomada dos "diálogos" e em cumprir o acordo já assinado, insistindo numa estratégia de contra-insurgência, inviabilizou a possibilidade de o EZLN deixar as armas para se unir à FZLN que, por sua vez, se tornou apenas mais um grupo zapatista no conjunto muito mais amplo da sociedade civil conectada direta ou indiretamente ao EZLN e às comunidades autônomas zapatistas. Essa situação começaria a mudar apenas em 2005.

Apesar dos impasses, um outro tipo de comunicação e envolvimento político vinha surgindo com o zapatismo, ampliando o seu alcance para o mundo todo e para os mais variados tipos de movimentos, instituições e grupos sociais. Marcos parecia já perceber isso em 1995, quando fez o seu escaravelho Durito comentar a importância da autonomia da CND em relação ao EZLN e aos partidos políticos, bem como do seu caráter amplo, plural, criativo, capaz de realizar "despropósitos", tais como "o diálogo em meio aos tanques" e "campanhas humanitárias em meio a uma crise profunda". Disse que se não fosse crescer muito, o que importava era a qualidade, e o que mais nos importa nesta leitura: 
se a CND não fosse o "espaço amplo" para este movimento da sociedade civil, esta criaria os seus próprios espaços. "Há que aprender muito, todavia. Este país tem muito o que aprender sobre si mesmo" (EZLN, 1995, pp. 314-322). Era exatamente o que estava acontecendo. Desde meados dos anos 1980, a sociedade civil mexicana estava criando seus próprios espaços, teias espontâneas e redes formalizadas de comunicação e solidariedade, processo que se intensificou a partir da eclosão do zapatismo em 1994. Antes do levante, prevalecia a fragmentação, até porque os novos movimentos surgiam ligados a uma variedade muito grande de identidades e interesses das chamadas "minorias", e porque as grandes organizações populares eram ainda herança do regime corporativo do PRI. Mas Chiapas renovou a perspectiva de uma transformação geral da nação e, depois, do mundo. Forneceu um tema forte, atraente, lúdico, novo e sempre em renovação, com um repertório performático maleável que facilmente podia ser apropriado, ressignificado, e permitia a realização de práticas de solidariedade que não implicavam necessariamente compromissos programáticos mais sérios, de maneira que os grupos mais variados podiam se ligar a este fenômeno e, quando possível, entre si aproveitando os contatos, espaços e símbolos propiciados por ele. Em janeiro de 1999, o sociólogo Henrique de La Garza (entrevista, cidade do México) contou algo sobre a maneira como a sociedade civil estava se conectando no país, que soava muito inovadora na época: "estão fragmentados, sem uma coordenação central, cada um em sua luta particular, quando surgem causas comuns, todos se unem em grandes mobilizações". O México era um laboratório gigante para novas formas de associativismo e mobilização, tal como a relatada por La Garza, que foram importantes precursoras do amadurecimento e generalização mundial das "redes", conceituadas por Ortellado (2004) como formas relativamente novas de associação fluidas e descentralizadas, unifi- 
cadas apenas por alguns princípios gerais e objetivos específicos, o que torna possível o trabalho conjunto de grupos e pessoas muito diferente.

Quando estourou o levante em 1994, a Diocese de San Cristóbal de Las Casas e outras ONGs de Chiapas já tinham uma tradição de observação de direitos humanos e outros trabalhos de solidariedade e desenvolvimento local, já conectados internacionalmente. Segundo Reygadas (1994, pp. 79-81), nos "diálogos da Catedral" de 1994, e como resposta ao pedido do EZLN para a "sociedade civil" garantir a segurança do evento, a Conpaz, a Convergência de Organismos Civis Pela Democracia e o Fórum de Apoio Mútuo (FAM) articularam com as ONGs do resto do país a organização do Espaço Civil Pela Paz (Espaz), cujo papel foi além da proposta do EZLN. Participaram 679 pessoas de mais de 150 organizações de 24 estados do país, cada uma trazendo "suas próprias expectativas e seu imaginário social". O Espaz combinou a organização da segurança através dos "cinturones de paz" e do controle sobre o credenciamento, com a formação de comissões de análise e informação, apoio logístico e porta-vozes. Depois dos "diálogos", o Espaz teve continuidade através da organização da observação dos direitos humanos, produção, circulação de análises e informação e atividades de solidariedade com as comunidades indígenas, num trabalho comprometido com a justiça social e a transição democrática do país. Mesmo os espaços de comunicação e deliberação promovidos pelo EZLN contribuíam para a formação das novas teias e redes, como podemos notar neste relato sobre a consulta de 1994: Hernández R. (1997, pp. 141-144) na época era estudante e foi voluntário nas atividades da consulta, abordando as pessoas na rua para explicar sobre o EZLN, Salinas, o bispo Samuel Ruiz da Diocese de San Cristóbal e então convidá-las a responder ao questionário. Ele conversou com jovens, velhos, homens, mulheres, estudantes e trabalhadores: 
"Enfim, pessoas que pouco a pouco descobriram que eram parte da Sociedade Civil, desconhecida para a maioria das pessoas antes que o Exército Zapatista nos falasse de sua existência [...] O mais reconfortante era ver que as pessoas se interessavam e respondiam ao questionário, viam as fotografias e os vídeos, falavam e escutavam e, ainda mais, em ocasiões, manifestavam disposição para difundir a consulta do EZLN entre os seus. Vaya, dentro de nossas possibilidades, participávamos.”

A proposta de uma "sociedade civil" organizada horizontalmente e através de novas formas de representação política, sem uma vanguarda, bem como a construção de espaços de comunicação e deliberação "face a face" e ações participativas reforçaram um fenômeno que ocorre sempre em alguma escala nos espaços dos movimentos sociais e em outras situações: a formação de teias e grupos horizontais de comunicação política que, geralmente, não são institucionalizados. Mas, se tradicionalmente esses grupos e teias se mantinham marginais no processo político, a sociedade civil valorizou-as, fortaleceu-as e passou a vê-las como constituintes da própria democracia em processo de construção, formalizando-as como redes, coletivos e autonomias. Para além dos espaços e organizações com suas situações de deliberação e representação, a "palavra" da "sociedade civil" ressignificava-se para toda e qualquer forma de comunicação política ou com efeitos políticos, extrapolando também os limites tradicionais dos temas, línguas, linguagens e gêneros que costumam estar associados à política: intensificava-se o baile entre performances. Ora, as transformações sociais não decorrem mecanicamente de deliberações autorizadas institucionalmente. A maior parte delas acontece com mudanças nos valores e significados que orientam os atores ou performers sociais, em processos que encerram sempre uma dimensão comunicativa. Com o fracasso da CND e o fecha- 
mento do Governo para a participação direta da população através dos fóruns e dos "diálogos", foram prevalecendo nas performances da "sociedade civil" essas novas experiências de teias, redes, coletivos, e reduzindo-se as fronteiras entre a política e outras práticas, como a arte, o jornalismo, a pesquisa e a produção econômica, que visam à justiça social. Em conjunto, são formas de transformação social que, ao mesmo tempo, bebem e são fonte da interlocução horizontal, seja ela deliberativa ou não, mediada ou "face a face", tendo um horizonte em que a democracia que se busca é colocada em prática na própria busca, e cuja forma final é desconhecida e inatingível, já que é fruto de um baile que não tem fim.

O conceito de participação política, já menos preso ao de deliberação, aproxima-se do conceito de comunicação horizontal. Como mostra o relato de Hernandez R., esses processos participativos ou comunicativos estimularam e incrementaram-se com as mídias participativas e autônomas, da fotografia aos vídeos independentes. Trata-se da transformação estrutural da mídia, fortalecendo-se os meios cuja produção é independente e participativa, em detrimento dos meios de difusão monopólicos. Fanzines, produtoras, editoras e gravadoras independentes, pequenas bandas, jornais, rádios livres etc., as mais variadas formas de produção deslancharam. Quando o EZLN marchou para a cidade do México em 2001, e para se expressar livremente, Marcos chegou a visitar e utilizar as ondas da rádio livre Zapote, localizada na Escola Nacional de Antropologia e História (Enah), e, em 2003, nasceu a Rádio Insurgentes em Chiapas, ligada ao EZLN. A internet foi fundamental. Castells (1996, pp. 93-168), que se refere ao zapatismo como "primeiro movimento de guerrilha informacional", relata que graças à conexão entre ONGs mexicanas, mantidas pela Igreja Católica, e o Instituto de Comunicação Global em São Francisco (EUA), mantido por ativistas especialistas em informática, 
entre 1989 e 1993 formou-se a La Neta, uma rede alternativa de comunicação computadorizada no México, em Chiapas e nos EUA que conectava grupos femininos e que em Chiapas havia sido instalada para colocar 12 ONGs locais on-line, além do Núcleo de Defesa dos Direitos Humanos "Bartolomé de las Casas”. Essas organizações tiveram um importante papel na difusão de informações sobre o conflito. A transformação estrutural da mídia e o uso horizontal da internet facilitaram a formação voluntária de grupos de solidariedade com os indígenas de Chiapas em todo o mundo, bem como a ampliação em escala mundial do que estava ocorrendo com a sociedade civil mexicana. Sensível a esse processo, o EZLN convocou, na sua Quarta Declaração, os dois primeiros encontros internacionais realizados na Selva Lacandona em 1996: o Encontro Continental Pela Humanidade e Contra o Neoliberalismo, que começou em 4 de abril, e o Encontro Intercontinental Pela Humanidade e Contra o Neoliberalismo, iniciado em 27 de julho, também chamados de "Intergaláticos". No Intercontinental, que contou com a participação de mais de 3 mil ativistas de 42 países dos cinco continentes, foi proposta a formação da Internacional da Esperança, uma rede de comunicação e solidariedade, sem uma coordenação central, para a mudança social em todo o planeta. A expansão das novas teias "espontâneas" e redes formalizadas, fortalecidas pela invenção que faziam da internet e de outras técnicas de comunicação, já começava a dar forma às novas performances que ajudariam a dar corpo ao chamado movimento anticapitalista e suas espetaculares ações globais sem coordenação central, cujo ápice se deu no movimento contra a guerra do Iraque em 2003. A primeira "ação global", como são chamados os protestos sincronizados em todo o mundo sem uma coordenação central, ocorreu no fim de 1997 e começo de 1998, como reação ao "Massacre de Acteal" em que foram mortos por paramilitares 45 indígenas dentro de uma Igreja de Chia- 
pas, em sua maioria mulheres e crianças. Houve protestos em mais de 100 países, revelando a continuidade e o crescimento de uma sólida barreira feita de solidariedade internacional que impedia a intensificação da repressão, mesmo a praticada de maneira velada através de grupos paramilitares. As redes que os Intergaláticos ajudaram a formalizar, sobretudo quando impulsionadas por jovens, inventariam depois as táticas de sincronizar ainda mais as ações e realizálas nos dias das reuniões mais importantes de cúpula econômica mundial do movimento anticapitalista. Um exemplo é a rede Ação Global dos Povos, que começou a ser formada no II Encontro Intercontinental Pela Humanidade e Contra o Neoliberalismo realizado na Espanha em 1997. Para Padilla (s.d.), a luta contra o Tratado de Livre Comércio da América do Norte (TLC), envolvendo centenas de grupos do México, EUA e Canadá, ensinou muito aos ativistas sobre a utilidade da internet, experiência absorvida pelas "comunidades virtuais" que denunciaram a repressão contra os zapatistas em 1994 e 1995. Durante os anos 1990, os ativistas criaram inúmeras zonas novas nas quais "compartilham informação, discutem táticas e estratégias e avaliam as experiências próprias e as dos outros". Na segunda metade da década a quantidade de interlinks entre as lutas cresceu tanto que "transformaram ações meramente locais em feitos globais". A Ação Global dos Povos, diretamente inspirada nas redes zapatistas e unindo movimentos da América do Norte, Europa e Ásia, "lançou caravanas internacionais de mobilização e uma ação antiglobal em Genebra, em 1998”. Em 18 de junho de 1999, uma "ação global", sincronizando sem uma coordenação central as ações de protesto de grupos em todo o mundo contra a cúpula econômica do FMI realizada em Seattle, tornou famoso o chamado movimento anticapitalista. Mas esses grupos não se voltaram apenas ao espetáculo, nem poderia ser assim, já que o sentido das redes está justamente na flexibilidade capaz de abranger 
a diversidade. Surgiram importantes performances locais e danças entre elas, além de novos palcos: um exemplo é a rede Indymedia, atualmente formada por centenas de coletivos (os Centros de Mídia Independente - CMI) espalhados pelo planeta, organizados horizontalmente e dedicados à democratização das comunicações. Esta rede nasceu de um site criado durante os protestos de Seattle para que os ativistas pudessem trocar arquivos com informações alternativas à grande mídia, tendo recebido a participação de mais de um milhão de pessoas, e, atualmente, destaca-se pela manutenção de sites de publicação aberta - nos quais o consumidor de notícias, áudios e vídeos pode também ser o seu produtor. Entre performances com pouca ou muita visibilidade não se pode deixar de mencionar o fortalecimento das autonomias de indígenas na Bolívia e no Equador, de piqueteiros na Argentina, as ações para construção de um "poder popular" na Venezuela, entre outras. No Brasil, o II Encontro Americano pela Humanidade e Contra o Neoliberalismo de 1999, em Belém, ajudou a dar visibilidade a movimentos indígenas e a influenciar o Fórum Social Mundial, que incorporou vários aspectos dos encontros zapatistas, como a ênfase na comunicação não-deliberativa.

A dança é feita de idas e vindas. Em 2002 nasceu o CMIChiapas, dedicado sobretudo ao zapatismo, cujo site possui um link para se escutar programas da Rádio Insurgentes. A grande ação zapatista de 2003 foi mudar o nome dos antigos Aguascalientes para Caracóis e lançar nesses espaços as Juntas de Bom Governo: permaneciam os mesmos princípios de autogestão regional, mas foram tomadas medidas para fortalecê-los, tais como a separação maior entre a hierarquia militar do EZLN e a hierarquia civil democrática. Mas mudanças maiores vieram com a Sexta Declaração da Selva Lacandona de 2005, que tirou novamente da tópica do "avanço libertador" o interesse na capital do país. A Sexta reflete o esgotamento do nó que se formou em torno da 
demanda pelo cumprimento dos Acordos de San Andrés: a aliança com uma sociedade civil que acabou se revelando majoritariamente pertencente às camadas médias da sociedade e a aliança tácita com o PRD, único partido importante que tornava possível a esperança em avanços negociados com o Estado, mas que passou a ser considerado traidor por apoiar medidas contrárias aos interesses indígenas e pela responsabilidade em casos de repressão a movimentos populares. A "Sexta" veio com uma linguagem que remete antes à prosa cotidiana do que aos gêneros literários e místicos que tanto agradaram as camadas médias, e lançou a "Outra Campanha" que, paralelamente à campanha presidencial de 2006, tem sido uma longa peregrinação da Comissão Sexta do EZLN pelos mais variados recantos mexicanos, em busca da tão sonhada aliança com o povo. O EZLN tem procurado conhecer melhor os movimentos populares de seu país, protestar pela libertação de presos políticos, unifi78 car as forças populares que lutam por um mundo melhor, sem delegar a esperança a partidos políticos, e elaborar um "Programa Nacional de Lutas". Não apenas o EZLN saiu em caravana: por todos os lados. Até mesmo em Brasília a sociedade civil tem realizado campanhas para promover a "política além do voto" (lema dos ativistas brasileiros), as performances transformadoras locais. A "Outra" não apenas desdenha o Estado e os partidos, como também a grande mídia, uma vez que é feita de inúmeras pequenas performances pouco atraentes para ela. Mas há exceções, como o $L a$ Jornada, que possui em seu site na internet uma sessão especialmente dedicada à sua cobertura. O espetáculo veio por parte do Estado e da mídia corporativa: em maio de 2006, a repressão a floricultores da cidade de Atenco gerou a mobilização de inúmeros ativistas que se somaram a eles e que também foram reprimidos, resultando em 33 pessoas desaparecidas, 218 presos, 5 estrangeiros deportados, um adolescente assassinado e 30 mulheres violentadas pela polícia. 
A televisão distorceu tanto a informação, mostrando imagens de policiais sendo atacados, que chegou a pedir para que a polícia intensificasse a repressão. O EZLN interrompeu a "Outra" e acionou o seu "alerta vermelho", tradicionalmente usado para chamar a atenção da sociedade civil sobre o aumento da repressão ou do seu risco em Chiapas. Subitamente, os ativistas de Atenco eram parte da mesma causa ameaçada em Chiapas, ressignificação que ajudou a descentralizar a atenção mundial e nacional simpática ao zapatismo de Chiapas para outras lutas do país. Foram registradas centenas de protestos por Atenco no México e em mais de 30 países ao redor do mundo, o que antes acontecia apenas por Chiapas.

Atualmente, o México encontra-se em estado de ebulição. Em Oaxaca, a repressão aos professores da Sessão 22 do magistério levou outros movimentos a se mobilizarem e, juntos, formaram a Assembléia Popular do Povo de Oaxaca (APPO) e passaram a pedir a saída do governador Ulisses Ruiz. Esses movimentos têm procurado promover assembléias locais para garantir espaços de participação e a representatividade da APPO, e têm ocupado rádios e até a TV estatal. Há nesse estado uma longa tradição de lutas autonomistas e de apoio a rádios comunitárias, além de sites na internet como o CMI-Oaxaca. Finalmente, a nova fraude nas eleições presidenciais, que garantiu a eleição de Felipe Calderón, levou milhões à mobilização: no centro da cidade no México meia centena de acampamentos se formaram, e o PRD convocou para lá uma CND, inspirada naquela de 1994. Em 16 de setembro mais de um milhão de mexicanos se reuniram na praça central para declarar a vitória de López Obrador e propor um plebiscito para decidir sobre a realização de uma constituinte. A APPO participou da CND. O EZLN preferiu apenas retomar a "Outra", dirigindo-se agora aos Estados do norte, onde sempre teve menos apoio. No dia 6 de outubro de 2006, Calderón visitou Brasí- 
lia, sendo recebido por um ritual "festivo-culinário-políticocanibal” organizado pela Ação Dignidade Rebelde Candanga. Em Marília (SP), começou mais um evento "A Flor da Palavra”, da jornada que já passou por outras três cidades brasileiras promovendo a conexão entre pesquisas, artes, movimentos, ações presenciais, midiáticas e a formação de uma grande rede de comunicação e solidariedade.

A dança do EZLN entre os performers da sociedade civil ampliou o significado da "palavra" e da política contemporânea. A resistência de um povo, como afirma Certeau (1994), está nas colagens que chama de "artes de fazer" e que permite a ele conservar o papel de produtor (de coisas, usos e significados) mesmo diante de uma dominação urbanoindustrial que tenta reduzi-lo ao mero consumo. A "intensificação" de uma cultura, como aponta Sahlins (1997), ocorre justamente quando os seus membros são sujeito de colagens, nas quais ressignificam, a partir de suas tradições, as contribuições das outras culturas, mesmo ao enfrentar o capitalismo. O zapatismo, por sua vez, nos indica o quanto a força dessas colagens está ligada a processos comunicativos rizomáticos. Processos assim sempre estiveram presentes na história da política, mas a modernidade recusou a eles a legitimidade, os marginalizou em relação à "razão" que, supostamente, legitimou tanto o poder do Estado ocidental quanto as formas "científicas" das lutas sociais guiadas por elites que centralizam dados e planejamento. É por este império da "razão" que as lutas indígenas mexicanas, antes do EZLN, eram chamadas "lutas camponesas". No atual contexto de crise dos Estados nacionais, a dança do EZLN e da sociedade civil tem ajudado a valorizar o papel mais vasto da cultura e da sociedade no processo político. Há nisso algo da noção foucaultiana de que o poder não está concentrado no Estado, mas difuso em toda a sociedade, de maneira que performances de todo tipo podem gerar transformações igualmente importantes. $\mathrm{O}$ baile insinua a necessidade de 
que a política se liberte da "razão" ocidental e admita outros "mundos", entre os quais tecer o "mundo onde caibam muitos mundos", conectando as razões "que brotam do coração", as estéticas das diversas identidades que se renovam e revitalizam sua dignidade na valorização das tradições e no contato transformador com as outras identidades, inventando-se possibilidades de interlocução mediada e não mediada que correspondem à própria invenção da democracia. É como se eles dissessem a cada um de nós: "queremos ouvir sua palavra".

\section{Guilherme Gitahy de Figueiredo}

é mestre em Ciência Política pela Unicamp e professor de Antropologia da Universidade do Estado do Amazonas

\section{Referências bibliográficas}

ARENDT, H. 2002. A condição humana. $10^{a}$ ed. Rio de Janeiro: Forense Universitária.

BRIGGS, A.; BURKE, P. 2004. Uma história social da mídia: de Gutemberg à internet. Rio de Janeiro: Jorge Zahar, 377p.

CASTELLS, M. 1999. A era da informação: economia, sociedade e cultura. São Paulo: Paz e Terra, 2 vols.

CERTEAU, M. de. 1994. A invenção do cotidiano: 1. Artes de fazer. Petrópolis: Vozes, 351p.

COHEN, R. 2004. Performance como linguagem. São Paulo: Perspectiva, 176p. EZLN. 1994. Documentos e comunicados. México DF: Era, ${ }^{\circ} 1,332 \mathrm{p}$. 1995. Documentos e comunicados. México DF: Era, $\mathrm{n}^{\circ} 2,471 \mathrm{p}$.

FIGUEIREDO, G. G. de. 2006. A guerra é o espetáculo. Origens e transformações da estratégia do EZLN. São Carlos, SP: Rima/FAPESP.

GEERTZ, C. 1989. A interpretação das culturas. Rio de Janeiro: Guanabara Koogan,

GORDILLO Y ORTIZ, O. 1994. "El EZLN: una aproximación bibliográfica". IN: SORIANO HERNÁNDEZ, S. (coord.). A proposito de la insurgencia en Chiapas. México: ADICH, pp. 123-142.

HERNÁNDEZ R., G. 1997. "Testemunho: a mesa da sociedade civil”. In: Memorial de Chiapas; pedacitos de historia. México DF: La Jornada, pp. 141-144.

ORTELLADO, P.; RYOKI, A. 2004. Estamos vencendo: resistência global no Brasil. São Paulo: Conrad. 
PADILLA FERNÁNDEZ, A. J. 2004. "Comunicación y política en el ciberespacio". Comunicacion.Venezuela: centro gumilla, $\mathrm{n}^{\circ} 114$. Disponível em: http://www. gumilla.org.ve/Comunicacion/COM114/COM114_Padilla. Acesso em:jun. 2004.

ROVIRA, G. 1997. Mujeres de Maíz. México DF: Era.

SAHLINS, M. 1997. "O 'pessimismo sentimental' e a experiência etnográfica: por que a cultura não é um objeto em via de extinção". Partes I e II. Revista Mana, Rio de Janeiro, vol. 3, $\mathrm{n}^{\circ} 1$ e 2.

THOMPSON, J. B. 1998. A mídia e a modernidade: uma teoria social da mídia. Petrópolis: Vozes, 261p.

TREJO DELARBRE, R. 1994. Chiapas: la comunicación enmascarada; los medios y el pasamontañas. México DF: Diana, 383p.

ZIBECHI, RAUL. 2004. "Los impactos del zapatismo en América Latina". Ekientza Zuzena, $\mathrm{n}^{\circ}$ 31. Disponível em: http://www.nodo50.org/ekintza/ article.php3?id_article=103. Acesso em: 6 out. 2006.

\section{Filmes}

FITZCARRALDO. 1982. Diretor e produtor: Werner Herzog. Interpretação: Klaus Kinsky; Cláudia Cardinale; José Lewgoy. Alemanha/Peru: Werner Herzog Filmproduktion. 1 DVD (157 min), son., color.

\section{Sites de referência}

EZLN: http://www.ezln.org/

Indymedia - CMI Chiapas: http://chiapas.mediosindependientes.org/

Rádio Insurgentes: http:/ /www.radioinsurgente.org/

Rádio Zapote: http:/ / www.radiozapote.cjb.net/ 
majority than their unchallenged counterparts. Among challenged presidents, the presence or absence of large street protests demanding they be removed from office is then crucial in determining their fates. These developments confound several core assumptions about presidential regimes: that presidential terms are firmly fixed, that populations cannot withdraw as well as grant presidential mandates, and that the consequences of political conflict in presidentialism are democratic breakdown.

Keywords: Presidentialism; Street challenges; Electoral mandates; South America.

\section{VAMOS AO BAILE: GINGAS DA COMUNICAÇÃO E DA PARTICIPAÇÃO NO ZAPATISMO}

\section{GUILHERME GITAHY DE FIGUEIREDO}

Entre 1983, ano em que foi criado como órgão das Forças de Libertação Nacional, até 1996, ano do I Encontro Intercontinental pela Humanidade e Contra o Neoliberalismo realizado em plena selva mexicana, o Exército Zapatista de Libertação Nacional (EZLN) viveu uma lenta e decisiva transformação: de guerrilha clássica a movimento pacífico que constrói "um mundo onde caibam muitos mundos", por meio da invenção de mecanismos de participação e comunicação. Este texto analisa essas novas maneiras de fazer política que têm sido cultivadas nas relações entre o EZLN e a por ele denominada "sociedade civil", que são inúmeros grupos a ele associados por laços de comunicação e solidariedade.

Palavras-chave: Zapatismo; Sociedade civil; México.

\section{LET'S GO TO THE BALL: SWINGS OF COMMUNICATION AND PARTICIPATION IN ZAPATISM}

Since 1983, year when it was created as an agency of the National 
Liberation Forces, until 1996, year of the first International Meeting for Humanity and Against Neoliberalism, organized in Mexican jungle, the Zapatista Army of National Liberation (ELZN) lived a slow and decisive transformation: from a classic guerrilla to a pacific movement which builds "one world that fits many worlds", through the invention of practices of participation and communication. This text analyses these new ways of doing politics that are being cultivated between the ELZN and what it calls "civil society", the countless groups connected to it through communication and solidarity ties.

Keywords: Zapatism; Civil society; Mexico.

\section{VINTE ANOS DEPOIS: A CONSTRUÇÃO DEMOCRÁTICA BRASILEIRA VISTA DA PERIFERIA DE SÃO PAULO}

\section{GABRIEL DE SANTIS FELTRAN}

Os movimentos sociais sempre buscaram estatuto político. Este artigo conta a história de um desses atores, o Movimento de Defesa do Favelado (MDF), que desde o final dos anos 1970 até os dias de hoje atua na periferia leste da cidade de São Paulo. Ao narrar essa história de trinta anos, vinte dos quais vividos sob a "nova democracia", o texto destaca as diferentes modalidades de relação entre os setores populares e a esfera política no Brasil contemporâneo. De um lado aparecem as tentativas de diluir a fronteira que bania, durante o regime autoritário, os segmentos populares da representatividade política; de outro lado, encontram-se novas fronteiras que, ainda que sob um regime pautado pela universalidade formal de direitos, se repõem hoje entre os setores populares e o mundo político.

Palavras-chave: Movimentos sociais; Periferia; São Paulo; Democracia; Representação. 